\title{
Association of Polymorphisms of Chicken Adipose Differentiation- related Protein Gene with Carcass Traits
}

\author{
Xiaoling Zhao ${ }^{1}$, Yiping $\mathrm{Liu}^{1}$, Xiaosong Jiang ${ }^{2,3}$, Huarui $\mathrm{Du}^{2,3}$ and Qing $\mathrm{Zhu}^{1}$ \\ ${ }^{1}$ College of Animal Science and Technology, Sichuan Agricultural University, Yaan, Sichuan, 625014, China \\ ${ }^{2}$ Sichuan Animal Science Academy, Chengdu, Sichuan, 610066, China \\ ${ }^{3}$ Sichuan Daheng Poultry Breeding Company, Chengdu, Sichuan, 610066, China
}

\begin{abstract}
Adipose differentiation-related protein (ADFP) plays an important role in regulating lipid storage and affecting body fat distribution. The objective of the current research was to identify the polymorphisms in chicken $A D F P$ gene and their associations with carcass traits. We screened all coding sequence and part of introns (totally $2155 \mathrm{bp}$ ) of the $A D F P$ gene by using single strand conformation polymorphism method in individuals from Sanhuang chicken, Mountainous Black-bone chicken and a commercial crossbred chicken (totally 427 birds). Three novel single-nucleotide polymorphisms were found in intron 4 (SNP1), intron 5 (SNP2) and exon 8 (SNP3), respectively. The association analyses showed that genotypes of SNP 1 were significantly associated with abdominal fat weight and percentage of abdominal fat $(P<0.05)$, genotypes of SNP2 were significantly associated with breast muscle weight and percentage of abdominal fat $(P<0.05)$, and the main haplotype/ haplotypes combination (their frequencies were higher than $5 \%$ ) were marginally significantly associated with breast muscle weight, abdominal fat weight, and percentage of abdominal fat $(0.05<P<0.1)$. Haplotype $\mathrm{H} 2$ (A-C-A) was an advantageous haplotype for breast muscle weight and H5 (T-C-G) was an advantageous haplotype for weight and percentage of abdominal fat. Conversely, H3H3 (A-T-G/A-T-G) was a disadvantage haplotype combination for accumulation of abdominal fat. These results suggested that polymorphisms of $A D F P$ gene were associated with carcass traits, especially with fatness traits. $A D F P$ is a potential major gene or in close linkage disequilibrium with the QTL affecting fatness traits in chickens.
\end{abstract}

Key words: adipose differentiation-related protein, carcass traits, chicken, fat, polymorphism

J. Poult. Sci., 46: 87-94, 2009

\section{Introduction}

It is well-known that broilers exhibit an increase in physiological disorders such as over-accumulated abdominal and subcutaneous fat, with increasing growth rate and breast muscle percentage. Redundant fat in the abdomen and under skin leads to the depression of feed efficiency and decrease of meat quality (Zhang et al., 2007). Thus, genetic factors which influence fat deposition have been intensive research topics in poultry (Zerehdaran, et al., 2004; Wang et al., 2006). Previous studies have found over ten candidate genes controlling fat deposition (Qiu et al., 2006; Wang et al., 2006; Wu et al., 2006; Zhang et al., 2006; Lei et al., 2007). Unfortunately, none of them could meet the needs of marker-assisted selection (MAS) of fatness traits in the chicken.

Adipose differentiation-related protein (ADFP) plays a critical role in lipid metabolism and thus affects body fat

Received: March 5, 2008, Accepted: November 18, 2008

Correspondence: Prof. Q. Zhu, College of Animal Science and Technology, Sichuan Agricultural University, Yaan, Sichuan province, 625014, China. (E-mail: zhuqing5959@163.com) distribution and regulation. ADFP, also named adipophilin, is generally upregulated in parallel with stored lipid during lipid droplet formation. It is present on the surface of lipid droplets from the earliest time of their synthesis (Imamura et al., 2002; Wang et al., 2003; Wolins et al., 2005). Exogenous expression of ADFP leads to an increase in neutral lipid mass and overaccumulation of lipid droplets (Magnusson et al., 2006; Prats et al., 2006; Listenberger et al., 2007). ADFP over-expression in cultured hepatocytes simultaneously slows triacylglycerol (TAG) turnover and decreases TAG secretion in very low density lipoprotein (Magnusson et al., 2006). Furthermore, inhibition of $A D F P$ expression in mice significantly reduces hepatic TAG accumulation (Chang et al., 2006).

Previous studies have suggested that $A D F P$ is a possible candidate gene for human type II diabetes and fat deposition in pigs (Wu et al., 2004; Kim et al., 2005). In this study, we supposed that $A D F P$ gene was a candidate gene for MAS of fatness traits in the chicken. The objectives of the current study were to identify the polymorphisms in the exons of $A D F P$ gene using the single-strand conformation polymorphism (SSCP) method and to evaluate the 
genetic effects of these polymorphisms on carcass traits, especially fatness traits in the chicken.

\section{Materials and Methods}

\section{Resource Populations}

Birds (male: female $=1: 1$ ) used in this study were from three chicken breeds: Mountainous Black-bone chicken (MB; $n=66)$, Sanhuang chicken $(\mathrm{SH} ; n=123)$ and a commercial crossbred (CC) chicken $(n=238)$. The CC breed consisted of five purebreds [S03 $(n=29), \mathrm{S} 01 \quad(n=$ 30), D99 $(n=30), \mathrm{S} 02(n=30)$ and S05 $(n=29)]$ and three crossbreds [S01 $\times \mathrm{S} 10(n=30), \mathrm{S} 01 \times \mathrm{D} 99(n=30)$, S01 $\times$ S05 $(n=30)$ ] from the Sichuan Daheng Poultry Breeding Company (Zhang et al., 2008). The MB chicken, a native breed in the Sichuan Province, has spotty feathers and black or yellow skin. These chickens have favorable meat quality. The $\mathrm{SH}$ chicken is an indigenous breed in the Guangdong Province. It was named because of its yellow plumage, skin and shanks and has a high meat quality. All birds were hatched on the same day, housed on the deep-litter bedding, and moved to the growing pens at $7 \mathrm{wk}$ of age. Birds had access to feed (commercial corn-soybean diets meeting NRC requirements) and water ad libitum.

\section{Phenotyping for Carcass Traits}

Prior to sacrificing at 90 days of age, the birds were fasted for $12 \mathrm{~h}$ and blood was collected for genomic DNA isolation by phenolic extraction (Salkinoja-Salonen et al., 1989). These DNA samples were used for genotyping the $A D F P$ gene. The body weight (BW) and seven carcass traits were then measured. These included: carcass weight (CW), semi-eviscerated weight (SEW), eviscerated weight (EW), breast muscle weight (BMW), leg muscle weight (LMW), abdominal fat weight (AFW) and subcutaneous fat thickness (SFT). The CW was measured on the chilled carcass without feathers. The SEW was measured with the trachea, esophagus, gastrointestinal tract, spleen, pancreas, and gonads removed. The EW was measured on the SEW after the removal of the head, claws, heart, liver, gizzard, glandular stomach, and abdominal fat. The SFT was measured at the caudal spondyle including the skin and fat with a vernier caliper after dressing. The ratios of AFW to $\mathrm{CW}$ were calculated as percentage of abdominal fat (PAF). Intramuscular fat (IMF) was extracted with Soxhlet extraction technique (DeRosa et al., 1983), and expressed as the weight per one hundred gram dry breast muscle.

\section{Amplification and Population Genotyping}

Nine primer pairs were designed using OLIGO 6.0 software (Molecular Biology Insights, Inc., Cascade, Co.) to amplify the coding sequence and part of introns of ADFP gene according to GenBank database sequences (Accession No: NC_006127, GI: 427237) (Table 1). Primers were synthesized by TaKaRa Biotechnology Co., Ltd (Dalian, China).

PCR amplification was performed in a total volume of $10 \mu \mathrm{L}$ containing $0.8 \mu \mathrm{L}(50 \mathrm{ng} / \mu \mathrm{L})$ template, $5 \mu \mathrm{L} 2 \times$ Taq PCR MasterMix (Beijing Tianwei Biology Technique Corporation), and $0.3 \mu \mathrm{L}$ of each primer $(10 \mathrm{pmol} / \mu \mathrm{L})$. The PCR reactions were carried out at $94^{\circ} \mathrm{C}$ for $4 \mathrm{~min}$, followed by 35 cycles of $94^{\circ} \mathrm{C}$ for $30 \mathrm{~s}, 50^{\circ} \mathrm{C}$ (or other annealing temperatures depicted in Table 1) for $30 \mathrm{~s}, 72^{\circ} \mathrm{C}$ for $1 \mathrm{~min}$ and a final elongation at $72^{\circ} \mathrm{C}$ for $8 \mathrm{~min}$. PCR products were resolved by $1 \%$ agarose gel, and the gel was analyzed on a gel imaging system (Gel Doc ${ }^{\mathrm{TM}}$ EQ1708060). Two $\mu \mathrm{L}$ of each PCR products was denatured at $98^{\circ} \mathrm{C}$ for $10 \mathrm{~min}$, cooled on ice for $5 \mathrm{~min}$, and then separated by polyacrylamide gel $(12 \%)$ electrophoresis at $10 \mathrm{~V} / \mathrm{cm}$ and $10^{\circ} \mathrm{C}$ for $10 \mathrm{~h}$. After electrophoresis, the gel was silver stained.

The genotypes were confirmed by direct sequencing using BigDye Terminator Chemistry on ABI 3700 (ABI, Applied Biosystems, Foster City, CA, USA).

\section{Statistical Analysis}

Single locus analyses

The genetic effects of the polymorphisms were tested using analysis of GLM in the SAS V8.02 package (SAS Institute Inc., Cary, NC). The following model was used: $\mathbf{Y}=\mu+\mathbf{B}+\mathbf{S}+\mathbf{G}(\mathbf{S})+\mathrm{bX}+\mathrm{e}$, where $\mathbf{Y}=$ the traits measured; $\mu=$ the population mean; $\mathrm{B}=$ the fixed breed/line effect; $S=$ the fixed sex effect; $G(S)=$ the nested effect of genotype within sex; $\mathrm{e}=$ the residual random effect; $b=$ the regression coefficients of the linear regressions on $\mathrm{X}$ (BW). Regression effect was considered because the BW

Table 1. Detailed information of the primers used for the single nucleotide polymorphism

\begin{tabular}{cllcc}
\hline \hline $\begin{array}{c}\text { Primers } \\
\text { number }\end{array}$ & \multicolumn{1}{c}{$\begin{array}{c}\text { Forward Primer } \\
\left(5^{\prime}-3^{\prime}\right)\end{array}$} & \multicolumn{1}{c}{$\begin{array}{c}\text { Reverse Primer } \\
\left(5^{\prime}-3^{\prime}\right)\end{array}$} & $\begin{array}{c}\text { Annealed } \\
\text { temperature } \\
\left({ }^{\circ} \mathrm{C}\right)\end{array}$ & $\begin{array}{c}\text { Product } \\
\text { length } \\
(\mathrm{bp})\end{array}$ \\
\hline 1 & TGAAAGCCTGATGTTTAGTTA & CCACCCTCGACACGAT & 49.2 & 227 \\
2 & CGTGTCGAGGGTGGTA & GTAAGCACATCTGGATACAAA & 51.6 & 260 \\
3 & CCAGAACCTTAAATCAACTAT & TCATGGCTTCTAATCTGT & 47.9 & 247 \\
4 & TGTAGCTCTCCCTAGCAAAT & CTTCCCAAGACAGTGTTAATG & 51.7 & 247 \\
5 & ACTGTCTTGGGAAGTCGT & CATGCTCCCTCTCCACTATGA & 51.0 & 211 \\
6 & ACCTGTTTCTTTCCAATTAC & CCAACACTTGCATTTATACC & 51.9 & 253 \\
7 & TGGCTGTATTTCAGATCGAG & GTTTGCCAATATTACCTTGAC & 49.6 & 215 \\
8 & AGCACATTGAGTCAAGAACTC & TCATCCAGAGACTCCTTC A & 53.5 & 250 \\
9 & CATCCTCCTTCCAGGAACTA & CTGTGCAGTTTACTCGCTATT & 53.1 & 245 \\
\hline
\end{tabular}


of individuals was discrepant largely.

Haplotype analyses

Because the $A D F P$ gene was on the $\mathrm{Z}$ chromosome, there were no heterozygous females and the genetic status of females were haplotype. Haplotypes of male were reconstructed according to all detected SNPs using the program PHASE 2.0 (Stephens et al., 2001) based on the Bayesian algorithm. The genetic status of males was expressed as the combination of two haplotypes (diplotype configuration). Genetic effects of haplotype were performed with the same model mentioned above.

The data of all carcass traits were verified for normal distribution by Shapiro-Wilks test in SAS V8.02. None of them were normally distributed. Thus, the parameters of CW, SEW, EW, BMW, LMW, AFW and SFT were estimated on the square root scale before they were analyzed with GLM. The PAF and IMF traits were shifted and rescaled to give approximate normal distribution and equal variance, with parameters converted by arcsine transformation. Genotype/haplotype effect was considered significant at $P<0.05$ for F-test of type III sum of squares. Values were presented as least square means (LSM) \pm standard errors (SE) after LSM and SE were converted to their original status.

\section{Results}

\section{Base Variants of Amplified Fragments}

PCR amplification products of the third primer pairs, the fifth primer pairs and the last primer pairs presented in Table 1 were polymorphic. Three gel profiles were observed for each of them (Fig. 1). Sequencing results confirmed that SNP1 $(\mathrm{A} \rightarrow \mathrm{T})$, SNP2 $(\mathrm{C} \rightarrow \mathrm{T})$ and SNP3 $(A \rightarrow G)$ were located in intron 4 , intron 5 and exon 8 (at the 398th amino acid position) of $A D F P$ gene, respectively (Table 2). SNP3 was synonymous mutation based on the analyses results of DNAstar V7.10 software package (DNASTAR, Inc. WI. USA).

\section{Genotype and Allele Frequencies}

Genotype and allele frequencies for three SNPs were summarized in Table 2. The alleles $A$ of SNP1, $C$ of SNP 2 and $G$ of SNP3 were predominant in all male populations. They were also predominant in hens for most populations. Breed MB was non-informative in SNP1 and the line S03, S01 $\times$ D99, S01 $\times$ S05 and D99 were noninformative in SNP3. Thus breed MB was not included in the GLM analyses for genetic effect of SNP1 and line S03, S01 $\times$ D99, S01 $\times$ S05 and D99 were excluded in the GLM analyses for genetic effect of SNP3.

Haplotypes and Their Frequencies

Haplotypes constructed based on 3 SNPs and their

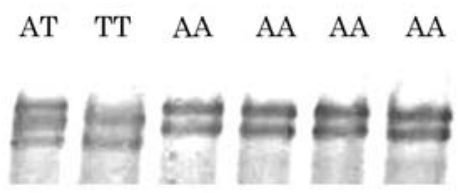

(1)

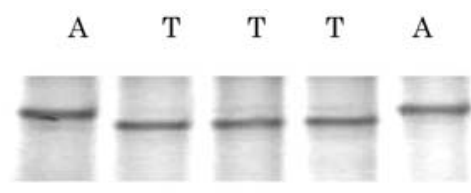

(2)

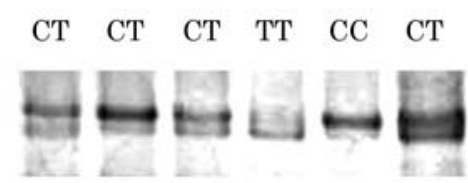

(3)

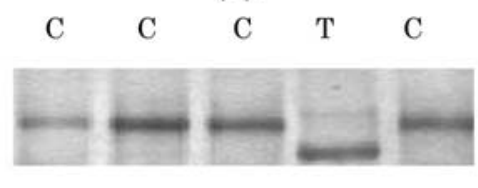

(4)

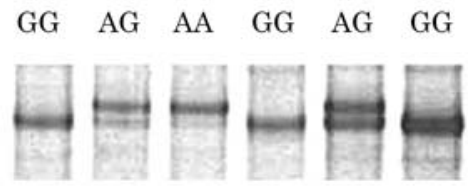

(5)

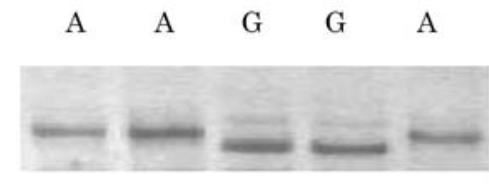

(6)

Fig. 1. Polyacrylamide gel electrophoresis picture of the polymorphic fragments.

(1) The profiles AT, AA and TT represented the heterozygote and two types of homozygote in cocks for SNP1, respectively. (2) The profiles $\mathrm{A}$ and $\mathrm{T}$ showed the two haplotypes in hens for SNP1. (3) The profiles $\mathrm{CT}, \mathrm{CC}$ and TT represented the heterozygote and two types of homozygote in SNP2, respectively. (4) The profiles $\mathrm{C}$ and T represented the two haplotypes in hens for SNP2. (5) The profiles AG, AA and GG represented the heterozygote and two types of homozygote in SNP3, respectively. (6) The profiles A and G represented the two haplotypes in hens for SNP3. 
Table 2. Details of the SNPs in ADFP gene

\begin{tabular}{|c|c|c|c|c|c|c|c|c|c|c|c|}
\hline \multirow{3}{*}{ SNPs } & \multirow{3}{*}{ Allele } & \multirow{3}{*}{ Location } & \multirow{3}{*}{$\begin{array}{l}\text { Chromosome } \\
\text { Position }^{2}\end{array}$} & \multirow{3}{*}{$\begin{array}{l}\text { Amino acid } \\
\text { position }\end{array}$} & \multirow{3}{*}{ Breed $^{5}$} & \multirow{3}{*}{$\begin{array}{c}\text { Allele } \\
\text { frequency } \\
\text { for cocks }{ }^{3}\end{array}$} & \multicolumn{5}{|c|}{ Genotype frequency ${ }^{4}$} \\
\hline & & & & & & & \multicolumn{3}{|c|}{ Cocks } & \multicolumn{2}{|c|}{ Hens } \\
\hline & & & & & & & $\mathrm{BB}$ & $\mathrm{AB}$ & AA & B & A \\
\hline \multirow[t]{10}{*}{ SNP1 } & $\mathrm{A} / \mathrm{T}^{1}$ & intron 4 & 33394913 & / & S03 & 0.11 & 0.79 & 0.21 & 0.00 & 0.80 & 0.20 \\
\hline & & & & & S01 & 0.13 & 0.73 & 0.27 & 0.00 & 1.00 & 0.00 \\
\hline & & & & & $\mathrm{S} 01 \times \mathrm{S} 10$ & 0.17 & 0.80 & 0.07 & 0.13 & 0.87 & 0.13 \\
\hline & & & & & S01 $\times$ D99 & 0.07 & 0.87 & 0.13 & 0.00 & 0.60 & 0.40 \\
\hline & & & & & $\mathrm{S} 01 \times \mathrm{S} 05$ & 0.07 & 0.93 & 0.07 & 0.00 & 0.93 & 0.07 \\
\hline & & & & & D99 & 0.00 & 1.00 & 0.00 & 0.00 & 0.93 & 0.07 \\
\hline & & & & & S02 & 0.30 & 0.40 & 0.60 & 0.00 & 0.93 & 0.07 \\
\hline & & & & & S05 & 0.00 & 1.00 & 0.00 & 0.00 & 0.87 & 0.13 \\
\hline & & & & & SH & 0.08 & 0.84 & 0.16 & 0.00 & 0.87 & 0.13 \\
\hline & & & & & MB & 0.00 & 1.00 & 0.00 & 0.00 & 1.00 & 0.00 \\
\hline \multirow[t]{10}{*}{ SNP2 } & $\mathrm{C} / \mathrm{T}^{1}$ & intron 5 & 33395676 & / & S03 & 0.04 & 0.93 & 0.07 & 0.00 & 0.80 & 0.20 \\
\hline & & & & & S01 & 0.30 & 0.47 & 0.47 & 0.06 & 0.20 & 0.80 \\
\hline & & & & & $\mathrm{S} 01 \times \mathrm{S} 10$ & 0.27 & 0.60 & 0.27 & 0.13 & 0.80 & 0.20 \\
\hline & & & & & S01 $\times$ D 99 & 0.33 & 0.47 & 0.40 & 0.13 & 0.67 & 0.33 \\
\hline & & & & & S01 $\times$ S05 & 0.23 & 0.53 & 0.47 & 0.00 & 0.27 & 0.63 \\
\hline & & & & & D99 & 0.27 & 0.47 & 0.53 & 0.00 & 0.87 & 0.13 \\
\hline & & & & & S02 & 0.17 & 0.80 & 0.07 & 0.13 & 0.00 & 1.00 \\
\hline & & & & & S05 & 0.14 & 0.71 & 0.29 & 0.00 & 0.73 & 0.67 \\
\hline & & & & & SH & 0.41 & 0.52 & 0.13 & 0.35 & 0.58 & 0.42 \\
\hline & & & & & MB & 0.20 & 0.78 & 0.03 & 0.19 & 0.21 & 0.79 \\
\hline \multirow[t]{10}{*}{ SNP3 } & $\mathrm{G} / \mathrm{A}^{1}$ & extron 8 & 33397903 & 398 & S03 & 0.00 & 1.00 & 0.00 & 0.00 & 1.00 & 0.00 \\
\hline & & & & & S01 & 0.40 & 0.47 & 0.27 & 0.27 & 0.27 & 0.73 \\
\hline & & & & & S01 $\times$ S10 & 0.00 & 1.00 & 0.00 & 0.00 & 0.87 & 0.13 \\
\hline & & & & & S01 $\times$ D 99 & 0.00 & 1.00 & 0.00 & 0.00 & 1.00 & 0.00 \\
\hline & & & & & $\mathrm{S} 01 \times \mathrm{S} 05$ & 0.00 & 1.00 & 0.00 & 0.00 & 1.00 & 0.00 \\
\hline & & & & & D99 & 0.00 & 1.00 & 0.00 & 0.00 & 1.00 & 0.00 \\
\hline & & & & & S02 & 0.43 & 0.27 & 0.60 & 0.13 & 0.67 & 0.33 \\
\hline & & & & & S05 & 0.14 & 0.71 & 0.29 & 0.00 & 0.67 & 0.33 \\
\hline & & & & & SH & 0.21 & 0.66 & 0.26 & 0.08 & 0.71 & 0.29 \\
\hline & & & & & MB & 0.23 & 0.59 & 0.32 & 0.06 & 0.71 & 0.29 \\
\hline
\end{tabular}

${ }^{1}$ Minor allele is in bold. ${ }^{2}$ Chromosome position based on NCBI Gallus_gallus-2.1. ${ }^{3}$ Minor allele frequency for cocks of each population in single locus. ${ }^{4} \mathrm{AA}=$ minor allele homozygote, $\mathrm{AB}=$ heterozygote, $\mathrm{BB}=$ major allele homozygote. ${ }^{5} \mathrm{~S} 03, \mathrm{~S} 01, \mathrm{D} 99, \mathrm{~S} 02$ and $\mathrm{S} 05$ were purebreds from the Sichuan Daheng Poultry Breeding Company; S01 $\times$ S10, S01 $\times$ D 99 and S01 $\times$ S05 were crossbreds from the Sichuan Daheng Poultry Breeding Company; $\mathrm{SH}=$ Sanhuang chicken, $\mathrm{MB}=$ Mountainous Black-bone chicken.

frequencies in cocks and hens were shown in Table 3. Eight haplotypes were identified in 427 chickens, in which the five most abundant ones (their frequencies were higher than 5\%), designated $\mathrm{H} 1$ (A-C-G), H2 (A-C-A), H3 (A-T-G), H4 (A-T-A) and H5 (T-C-G), accounted for $97.97 \%$ of the cocks and $94.45 \%$ of the hens. The haplotype $\mathrm{H} 1$ was predominant in all populations. As the $A D F P$ gene was on $\mathrm{Z}$ chromosome, all diplotypes were from the male. Eighteen diplotypes were obtained based on these eight haplotypes for cocks. Among them, the main diplotypes (their frequencies were higher than $5 \%$ ) accounted for $81.51 \%$ of the cocks.

\section{Marker-Trait Association Analyses}

The effect of single polymorphisms and haplotype/ diplotypes on all carcass traits (CW, SEW, EW, BMW, LMW, AFW, SFT, IMF and PAF) was estimated with GLM. Genotypes of SNP1 had a significant effect on
AFW (type III $F=2.83, P=0.0385$ ) and PAF (type III $F$ $=3.09, P=0.0273)$. Genotypes of SNP2 had a significant effect on BMW (type III $F=2.76, P=0.0421$ ) and PAF (type III $F=2.76, P=0.0421$ ). And haplotype/diplotypes had a marginally significant effect on BMW (type III $F=$ 1.94, $P=0.0530$ ), AFW (type III $F=1.74, P=0.0872$ ) and PAF (type III $F=1.93, P=0.0544$ ). No effect of genotypes at SNP3 on carcass traits approached a statistically significant level according to total type III probability of significance.

Table 4 presented the summary of the association analyses of the $A D F P$ polymorphisms and carcass traits. In SNP1, the AFW and PAF of genotype $A$ and $T$ (45.55 $\mathrm{g}, 49.71 \mathrm{~g}, 2.96 \%$ and $3.30 \%$ ) in hens were great significantly higher than those of $A A$ and $A T(21.13 \mathrm{~g}, 30.48$ g, $1.38 \%$ and $2.07 \%)$ in cocks, respectively $(P<0.01)$. And the birds with genotype $A T$ had higher AFW and 
Table 3. Haplotypes constructed with 3 single nucleotide polymorphisms (SNP) and their frequencies in cocks and hens

\begin{tabular}{|c|c|c|c|c|c|c|c|c|c|}
\hline \multirow{2}{*}{ Haplotype } & \multicolumn{3}{|c|}{ SNP } & \multicolumn{2}{|c|}{ Frequency $(\%)$} & \multirow{2}{*}{ Diplotype } & \multirow{2}{*}{$\begin{array}{c}\text { Frequency } \\
(\%)\end{array}$} & \multirow{2}{*}{ Diplotype } & \multirow{2}{*}{$\begin{array}{c}\text { Frequency } \\
(\%)\end{array}$} \\
\hline & SNP1 & SNP2 & SNP3 & Cocks $(211)^{1}$ & Hens $(216)^{1}$ & & & & \\
\hline $\mathrm{H} 1$ & A & $\mathrm{C}$ & G & 56.22 & 37.96 & $\mathrm{H} 1 \mathrm{H} 1$ & 36.97 & $\mathrm{H} 2 \mathrm{H} 6$ & 0.47 \\
\hline $\mathrm{H} 2$ & A & $\mathrm{C}$ & A & 9.63 & 6.02 & $\mathrm{H} 1 \mathrm{H} 2$ & 10.90 & $\mathrm{H} 3 \mathrm{H} 4$ & 3.79 \\
\hline $\mathrm{H} 3$ & A & $\mathrm{T}$ & G & 20.42 & 28.24 & $\mathrm{H} 1 \mathrm{H} 3$ & 16.11 & $\mathrm{H} 3 \mathrm{H} 5$ & 0.47 \\
\hline $\mathrm{H} 4$ & A & $\mathrm{T}$ & A & 5.68 & 16.67 & $\mathrm{H} 1 \mathrm{H} 5$ & 8.53 & $\mathrm{H} 3 \mathrm{H} 7$ & 0.95 \\
\hline H5 & $\mathrm{T}$ & $\mathrm{C}$ & G & 6.02 & 5.56 & $\mathrm{H} 3 \mathrm{H} 3$ & 9.00 & $\mathrm{H} 3 \mathrm{H} 8$ & 0.47 \\
\hline H6 & $\mathrm{T}$ & $\mathrm{C}$ & A & 0.88 & 0.46 & $\mathrm{H} 1 \mathrm{H} 4$ & 2.84 & $\mathrm{H} 4 \mathrm{H} 4$ & 1.42 \\
\hline H7 & $\mathrm{T}$ & $\mathrm{T}$ & G & 0.85 & 4.63 & $\mathrm{H} 2 \mathrm{H} 2$ & 1.42 & $\mathrm{H} 4 \mathrm{H} 5$ & 0.47 \\
\hline \multirow[t]{2}{*}{$\mathrm{H} 8$} & $\mathrm{~T}$ & $\mathrm{~T}$ & $\mathrm{~A}$ & 0.40 & 0.46 & $\mathrm{H} 2 \mathrm{H} 4$ & 2.37 & $\mathrm{H} 4 \mathrm{H} 8$ & 0.47 \\
\hline & & & & & & $\mathrm{H} 2 \mathrm{H} 5$ & 2.37 & $\mathrm{H} 5 \mathrm{H} 5$ & 0.95 \\
\hline
\end{tabular}

${ }^{1}$ The number in parentheses is the observed number in cocks or hens.

PAF than those of $A A(P=0.0052)$. In SNP2, the $C$ and $T$ hens had higher BMW (191.11 $\mathrm{g}$ and $192.09 \mathrm{~g})$ and PAF (2.91\% and $2.69 \%)$ than the $C C$ and $C T$ cocks $(166.33 \mathrm{~g}$, $165.44 \mathrm{~g}, 1.45 \%$ and $1.44 \%)(P<0.01)$ and the BMW and PAF of the $C C$ and $C T$ birds were significantly higher than those of $T T$ birds $(152.57 \mathrm{~g}$ and $0.96 \%)$, too $(P<$ $0.01)$. The main diplotypes were marginally significantly associated with BMW, AFW and PAF $(0.05<P<0.1)$. The $\mathrm{H} 2$ haplotype had more BMW than other haplotypes (H1, H3, H4 and H5) and haplotype combinations (H1 $\mathrm{H} 1, \mathrm{H} 1 \mathrm{H} 2, \mathrm{H} 1 \mathrm{H} 3, \mathrm{H} 1 \mathrm{H} 5$ and $\mathrm{H} 3 \mathrm{H} 3$ ). And haplotype $\mathrm{H} 5$ had highest AFW and PAF, compared with other haplotypes ( $\mathrm{H} 1, \mathrm{H} 2, \mathrm{H} 3$ and $\mathrm{H} 4)$ and haplotype combinations $(\mathrm{H} 1 \mathrm{H} 1, \mathrm{H} 1 \mathrm{H} 2, \mathrm{H} 1 \mathrm{H} 3, \mathrm{H} 1 \mathrm{H} 5$ and $\mathrm{H} 3 \mathrm{H} 3)$. It suggested that haplotype $\mathrm{H} 2$ was an advantageous haplotype for BMW and H5 was an advantageous haplotype for weight and percentage of abdominal fat. Conversely, diplotype $\mathrm{H} 3 \mathrm{H} 3$ was a disadvantage haplotype combination for accumulation of abdominal fat as its AFW and PAF were lowest compared with other diplotypes and haplotypes.

\section{Discussion}

The approach of using a candidate gene, selected on the basis of known relationships between physiology and production traits, is a useful method to investigate associations of gene polymorphisms directly, with certain traits of interest in farm animals (Rothschild et al., 1997; Jiang et al., 2000). Because the role of adipose differentiationrelated protein (ADFP) is controlling lipid droplet homeostasis (Brasaemle et al., 1997; Gross et al., 2006), research efforts have been increasingly directed toward the association of SNPs in ADFP gene and obesity-related diseases in humans, and fatness traits in livestocks. In the East Chinese population, $23 \mathrm{SNPs}$ of $A D F P$ gene were detected. The allelic and genotypic frequencies of the SNP located in ADFP gene promoter in population with type II diabetes were significantly different with those of the controls. Two missense mutations were typically transferred in two families with type II diabetes (Wu et al., 2004). Moreover, several sequence variations in por- cine $A D F P$ gene were observed from nine Korean native pig breeds (Kim et al., 2005). The biological role and the mapping localization of this gene indicate that the porcine $A D F P$ is a possible candidate gene for fat deposition and marbling traits. The chicken $A D F P$ gene, located in chromosome $\mathrm{Z}$, contains $7775 \mathrm{bp}$ including 8 exons and 7 introns. Two SNPs were detected in exon 1 (the first amino acid) and exon 8 (the 409th amino acid) (http:// www. ncbi. nlm. nih. gov / SNP / snp_ref. cgi? locusId = 427237). But, no association analysis of these two SNPs and carcass traits was reported.

In the current study, three novel SNPs of chicken $A D F P$ gene were identified. Although none of them leads to amino acid changes, the efficiency of transcription or translation of the $A D F P$ gene might be affected by these mutations (Nielsen et al., 2007). And the degree that mutations affected the efficiency of transcription or translation of the $A D F P$ gene might be different. So, the differences of the results of marker-trait association among the three SNPs were the differences of genetic effect brought on by the three SNPs. Interestingly, the results of single locus analyses and haplotype analyses showed that genotypes of SNP1 had significant effect on AFW and PAF, SNP2 had significant effect on BMW and PAF, and haplotype/diplotype had marginally significant effect on AFW, PAF and BMW $(0.05<P<0.1)$. These results were in accordance with adipose differentiation-related protein's function controlling metabolism of triglyceride and participating in the formation of lipid droplets, which supported our hypothesis that these mutations were associated with chicken carcass traits, especially fatness traits. The phenotype of carcass traits of each breed is not described in this manuscript, for all the three populations in this study were local chicken breeds for meat type and we initially failed to find the significant differences of the average of traits between breeds before we performed the marker-trait association analyses. If there are the differences of the average of traits between breeds, the linkage disequilibrium not always means the true linkage. Thus we only considered the nested effect of genotype within sex in the model used in this study. 
Table 4. Associations of $\boldsymbol{A D F P}$ polymorphisms and carcass traits in chickens

\begin{tabular}{|c|c|c|c|c|c|c|c|}
\hline \multirow{2}{*}{ Marker } & \multirow{2}{*}{ Genotype } & \multirow{2}{*}{ Number } & \multicolumn{5}{|c|}{ Traits $^{1}$} \\
\hline & & & CW (g) & SEW (g) & EW (g) & BMW (g) & LMW (g) \\
\hline \multirow[t]{5}{*}{ SNP1 } & AA & 147 & $1552.24 \pm 12.13$ & $1422.73 \pm 3.55$ & $1175.20 \pm 3.90$ & $171.92 \pm 2.26$ & $264.85 \pm 8.68$ \\
\hline & $\mathrm{AT}$ & 30 & $1527.85 \pm 25.47$ & $1414.19 \pm 7.48$ & $1156.16 \pm 8.16$ & $166.20 \pm 4.70$ & $260.36 \pm 18.32$ \\
\hline & TT & 12 & $1598.37 \pm 100.41$ & $1478.57 \pm 29.25$ & $1208.88 \pm 31.96$ & $176.56 \pm 18.82$ & $258.85 \pm 72.92$ \\
\hline & A & 148 & $1528.74 \pm 11.21$ & $1414.00 \pm 3.29$ & $1182.21 \pm 3.63$ & $197.79 \pm 2.25$ & $264.89 \pm 8.06$ \\
\hline & $\mathrm{T}$ & 24 & $1531.86 \pm 28.09$ & $1418.84 \pm 8.25$ & $1176.61 \pm 9.06$ & $196.81 \pm 5.63$ & $256.62 \pm 20.05$ \\
\hline \multirow[t]{5}{*}{ SNP2 } & $\mathrm{CC}$ & 130 & $1521.35 \pm 12.30$ & $1384.93 \pm 3.82$ & $1159.75 \pm 4.09$ & $166.33 \pm 2.23^{\mathrm{B} 2}$ & $255.43 \pm 8.28$ \\
\hline & $\mathrm{CT}$ & 47 & $1499.32 \pm 19.23$ & $1388.75 \pm 6.01$ & $1155.99 \pm 6.43$ & $165.44 \pm 3.51^{\mathrm{B}}$ & $258.71 \pm 13.16$ \\
\hline & TT & 34 & $1484.20 \pm 23.58$ & $1367.41 \pm 7.35$ & $1139.06 \pm 7.87$ & $152.57 \pm 4.16^{\mathrm{C}}$ & $253.94 \pm 16.12$ \\
\hline & $\mathrm{C}$ & 108 & $1487.25 \pm 13.09$ & $1374.38 \pm 4.09$ & $1157.01 \pm 4.40$ & $191.11 \pm 2.58^{\mathrm{A}}$ & $260.03 \pm 8.99$ \\
\hline & $\mathrm{T}$ & 108 & $1488.09 \pm 13.45$ & $1380.83 \pm 4.21$ & $1163.61 \pm 4.52$ & $192.09 \pm 2.65^{\mathrm{A}}$ & $253.11 \pm 9.11$ \\
\hline \multirow[t]{5}{*}{ SNP3 } & AA & 13 & $1438.52 \pm 41.58$ & $1312.66 \pm 11.90$ & $1098.84 \pm 12.39$ & $159.35 \pm 7.04$ & $243.64 \pm 28.50$ \\
\hline & $\mathrm{AG}$ & 44 & $1437.22 \pm 23.30$ & $1329.93 \pm 6.77$ & $1115.97 \pm 7.06$ & $162.53 \pm 4.00$ & $243.25 \pm 15.92$ \\
\hline & GG & 95 & $1466.64 \pm 16.57$ & $1323.09 \pm 4.74$ & $1116.19 \pm 4.95$ & $156.04 \pm 2.75$ & $244.83 \pm 11.17$ \\
\hline & $\mathrm{A}$ & 51 & $1423.30 \pm 21.13$ & $1313.87 \pm 6.09$ & $1121.35 \pm 6.40$ & $185.32 \pm 3.87$ & $241.85 \pm 14.35$ \\
\hline & G & 105 & $1425.10 \pm 15.41$ & $1323.22 \pm 4.46$ & $1116.51 \pm 4.66$ & $186.65 \pm 2.83$ & $252.20 \pm 10.64$ \\
\hline \multirow[t]{10}{*}{ Diplotype } & $\mathrm{H} 1 \mathrm{H} 1$ & 78 & $1555.19 \pm 16.95^{3}$ & $1395.29 \pm 4.76$ & $1172.09 \pm 4.69$ & $168.10 \pm 2.89$ & $258.24 \pm 11.41$ \\
\hline & $\mathrm{H} 1 \mathrm{H} 2$ & 23 & $1499.21 \pm 31.07$ & $1396.39 \pm 9.00$ & $1186.03 \pm 8.92^{3}$ & $175.37 \pm 5.59$ & $250.60 \pm 21.43$ \\
\hline & $\mathrm{H} 1 \mathrm{H} 3$ & 34 & $1508.29 \pm 25.02$ & $1398.30 \pm 7.12^{3}$ & $1165.84 \pm 6.99$ & $164.26 \pm 4.27$ & $266.42 \pm 17.39$ \\
\hline & $\mathrm{H} 1 \mathrm{H} 5$ & 18 & $1492.36 \pm 33.22$ & $1386.82 \pm 9.45$ & $1150.83 \pm 9.26^{4}$ & $160.88 \pm 5.64$ & $253.06 \pm 22.71$ \\
\hline & $\mathrm{H} 3 \mathrm{H} 3$ & 19 & $1489.97 \pm 33.35^{4}$ & $1380.02 \pm 9.47$ & $1157.69 \pm 9.34$ & $151.15 \pm 5.50^{4}$ & $253.79 \pm 22.87$ \\
\hline & H1 & 75 & $1501.75 \pm 17.25$ & $1387.28 \pm 4.90$ & $1170.79 \pm 4.84$ & $192.18 \pm 3.19$ & $268.93 \pm 12.02^{3}$ \\
\hline & $\mathrm{H} 2$ & 13 & $1492.73 \pm 39.56$ & $1369.54 \pm 11.17^{4}$ & $1173.48 \pm 11.12$ & $202.85 \pm 7.54^{3}$ & $245.95 \pm 26.75^{4}$ \\
\hline & $\mathrm{H} 3$ & 61 & $1498.24 \pm 19.01$ & $\overline{1393.32 \pm 5.42}$ & $1170.87 \pm 5.34$ & $196.33 \pm 3.55$ & $\overline{254.95 \pm 12.93}$ \\
\hline & $\mathrm{H} 4$ & 36 & $1492.11 \pm 25.11$ & $1390.04 \pm 7.16$ & $1177.06 \pm 7.08$ & $192.40 \pm 4.66$ & $255.60 \pm 17.18$ \\
\hline & H5 & 12 & $1508.38 \pm 41.24$ & $1391.80 \pm 11.67$ & $1161.31 \pm 11.47$ & $185.76 \pm 7.49$ & $253.35 \pm 28.16$ \\
\hline
\end{tabular}

${ }^{1} \mathrm{CW}=$ carcass weight, $\mathrm{SEW}=$ semi-eviscerated weight, $\mathrm{EW}=$ eviscerated weight, $\mathrm{BMW}=$ breast muscle weight, $\mathrm{LMW}=$ leg muscle weight, $\mathrm{AFW}=$ abdominal fat weight, $\mathrm{PAF}=$ percentage of abdominal fat, SFT $=$ subcutaneous fat thickness, $\mathrm{IMF}=\mathrm{Intramuscular}$ fat content.

${ }^{2}$ The least square means within a line lacking a common uppercase superscript differ great significantly $(P<0.01)$.

${ }^{3}$ The bold numbers represent the advantageous diplotypes.

${ }^{4}$ Underlined numbers represent the negative diplotypes.

However, usually the problem arises as to whether it is necessary to consider the variation in candidate genes as phased haplotypes or whether a single locus at-a-time approach might perform as well. Quite a few people (Morris and Kaplan, 2002; Horne and Camp, 2004) considered haplotype method has greater statistical power than tests based on the underlying single marker in view of the interaction between non-alleles and linkage disequilibrium between the SNPs. But Clark (2004) reported that the haplotype-based approach may perform worse than the single locus approach if the causal connection between SNP and a phenotype is truly driven by just a single SNP. The association results of single SNP/haplotypes with carcass traits in the current study confirmed the conclusion of Clark (2004).

There was no report showed the QTLs for chicken carcass traits localized at the ADFP gene area. However, in chromosome Z, there were 16 QTLs closely associated with growth traits. Especially, two of them affected abdominal fat weight as reported (Abasht et al., 2006). The data from the current study also showed that polymorphisms in chicken $A D F P$ gene were significantly associated with BMW, AFW and PAF. ADFP is a potential major gene or in close linkage disequilibrium with QTL affecting fatness traits in chickens.

\section{Acknowledgments}

We thank Dr. Guoqing Tang for giving good advice on data analyses and Dr. B. Timmons for critically reading the manuscript. We also thank Dingming Shu, Hao Qu and Zhiqing Yang for helps in managing the birds and collecting the data. This work was financially supported by Project of Provincial Eleventh-five-year Animal Breeding of Sichuan Province (Grant No: 2006YZGG-19). 
Table 4. (Continuation) Associations of $A D F P$ polymorphisms and carcass traits in chickens

\begin{tabular}{|c|c|c|c|c|c|c|}
\hline \multirow{2}{*}{ Marker } & \multirow{2}{*}{ Genotype } & \multirow{2}{*}{ Number } & \multicolumn{4}{|c|}{ Traits $^{1}$} \\
\hline & & & AFW (g) & SFT (mm) & $\operatorname{IMF}(\%)$ & PAF $(\%)$ \\
\hline \multirow[t]{5}{*}{ SNP1 } & AA & 147 & $21.13 \pm 1.36^{\mathrm{C} 2}$ & $3.17 \pm 0.08$ & $4.03 \pm 0.23$ & $1.38 \pm 0.10^{\mathrm{C} 2}$ \\
\hline & AT & 30 & $30.48 \pm 3.49^{\mathrm{B}}$ & $3.23 \pm 0.17$ & $4.44 \pm 0.48$ & $2.07 \pm 0.25^{\mathrm{B}}$ \\
\hline & TT & 12 & $27.87 \pm 13.85^{\mathrm{ABC}}$ & $3.41 \pm 0.53$ & $4.26 \pm 1.99$ & $1.79 \pm 0.97^{\mathrm{ABC}}$ \\
\hline & $\mathrm{A}$ & 148 & $45.55 \pm 1.85^{\mathrm{A}}$ & $4.33 \pm 0.10$ & $4.96 \pm 0.24$ & $2.96 \pm 0.31^{\mathrm{A}}$ \\
\hline & $\mathrm{T}$ & 24 & $49.71 \pm 4.89^{\mathrm{A}}$ & $4.56 \pm 0.21$ & $5.33 \pm 0.60$ & $3.30 \pm 0.35^{\mathrm{A}}$ \\
\hline \multirow[t]{5}{*}{ SNP2 } & $\mathrm{CC}$ & 130 & $21.31 \pm 1.41$ & $3.21 \pm 0.09$ & $4.03 \pm 0.23$ & $1.45 \pm 0.10^{\mathrm{B} 2}$ \\
\hline & $\mathrm{CT}$ & 47 & $21.26 \pm 2.24$ & $3.12 \pm 0.12$ & $3.84 \pm 0.30$ & $1.44 \pm 0.16^{\mathrm{B}}$ \\
\hline & TT & 34 & $14.45 \pm 2.30$ & $3.10 \pm 0.21$ & $4.21 \pm 0.33$ & $0.96 \pm 0.17^{\mathrm{C}}$ \\
\hline & $\mathrm{C}$ & 108 & $43.58 \pm 2.16$ & $4.34 \pm 0.11$ & $4.68 \pm 0.24$ & $2.91 \pm 0.16^{\mathrm{A}}$ \\
\hline & $\mathrm{T}$ & 108 & $41.04 \pm 2.15$ & $4.28 \pm 0.11$ & $4.11 \pm 0.23$ & $2.69 \pm 0.15^{\mathrm{A}}$ \\
\hline \multirow[t]{5}{*}{ SNP3 } & AA & 13 & $14.88 \pm 3.97$ & $3.21 \pm 0.09$ & $4.03 \pm 0.23$ & $1.45 \pm 0.10$ \\
\hline & $\mathrm{AG}$ & 44 & $17.62 \pm 2.39$ & $3.12 \pm 0.12$ & $3.84 \pm 0.30$ & $1.44 \pm 0.16$ \\
\hline & GG & 95 & $20.19 \pm 1.77$ & $3.10 \pm 0.21$ & $4.21 \pm 0.33$ & $0.96 \pm 0.17$ \\
\hline & $\mathrm{A}$ & 51 & $38.01 \pm 3.12$ & $4.34 \pm 0.11$ & $4.68 \pm 0.24$ & $2.91 \pm 0.16$ \\
\hline & $\mathrm{G}$ & 105 & $41.87 \pm 2.37$ & $4.28 \pm 0.11$ & $4.11 \pm 0.23$ & $2.69 \pm 0.15$ \\
\hline \multirow[t]{10}{*}{ Diplotype } & $\mathrm{H} 1 \mathrm{H} 1$ & 78 & $19.33 \pm 1.69$ & $3.20 \pm 0.11$ & $3.99 \pm 0.29$ & $1.30 \pm 0.12$ \\
\hline & $\mathrm{H} 1 \mathrm{H} 2$ & 23 & $19.36 \pm 3.31$ & $3.36 \pm 0.21$ & $3.81 \pm 0.42^{4}$ & $1.30 \pm 0.24$ \\
\hline & $\mathrm{H} 1 \mathrm{H} 3$ & 34 & $22.43 \pm 2.73$ & $3.19 \pm 0.15$ & $\overline{4.00 \pm 0.36}$ & $1.56 \pm 0.20$ \\
\hline & $\mathrm{H} 1 \mathrm{H} 5$ & 18 & $31.97 \pm 4.36$ & $3.09 \pm 0.23$ & $4.02 \pm 0.49$ & $2.24 \pm 0.32$ \\
\hline & $\mathrm{H} 3 \mathrm{H} 3$ & 19 & $18.63 \pm 3.38^{4}$ & $3.05 \pm 0.26^{4}$ & $3.92 \pm 0.42$ & $1.18 \pm 0.24^{4}$ \\
\hline & H1 & 75 & $\overline{43.70 \pm 2.60}$ & $\overline{4.24 \pm 0.14}$ & $4.68 \pm 0.29$ & $2.89 \pm 0.19$ \\
\hline & $\mathrm{H} 2$ & 13 & $35.86 \pm 5.51$ & $4.36 \pm 0.36$ & $5.53 \pm 0.61$ & $2.35 \pm 0.39$ \\
\hline & $\mathrm{H} 3$ & 61 & $42.65 \pm 2.83$ & $4.23 \pm 0.14$ & $3.97 \pm 0.28$ & $2.65 \pm 0.20$ \\
\hline & $\mathrm{H} 4$ & 36 & $39.20 \pm 3.62$ & $4.26 \pm 0.19$ & $4.18 \pm 0.35$ & $2.59 \pm 0.26$ \\
\hline & H5 & 12 & $50.30 \pm 6.73^{3}$ & $4.56 \pm 0.30^{3}$ & $\mathbf{5 . 5 7} \pm \mathbf{0 . 7 1 ^ { 3 }}$ & $3.42 \pm 0.49^{3}$ \\
\hline
\end{tabular}

${ }^{1} \mathrm{CW}=$ carcass weight, $\mathrm{SEW}=$ semi-eviscerated weight, $\mathrm{EW}=$ eviscerated weight, $\mathrm{BMW}=$ breast muscle weight, $\mathrm{LMW}=$ leg muscle weight, $\mathrm{AFW}=$ abdominal fat weight, $\mathrm{PAF}=$ percentage of abdominal fat, SFT $=$ subcutaneous fat thickness, $\mathrm{IMF}=\mathrm{Intramuscular}$ fat content.

${ }^{2}$ The least square means within a line lacking a common uppercase superscript differ great significantly $(P<0.01)$.

${ }^{3}$ The bold numbers represent the advantageous diplotypes.

${ }^{4}$ Underlined numbers represent the negative diplotypes.

\section{References}

Abasht B, Dekkers JCM and Lamont SJ. Review of quantitative trait loci identified in the chicken. Poultry Science, 85: 20792096. 2006.

Brasaemle DL, Barber T, Wolins NE, Serrero G, BlanchetteMackie EJ and Londos C. Adipose differentiation-related protein is an ubiquitously expressed lipid storage dropletassociated protein. Journal of Lipid Research, 38: 22492263. 1997.

Chang BH, Li L, Paul A, Taniguchi S, Nannegari V, Heird WC and Chan L. Protection against fatty liver but normal adipogenesis in mice lacking adipose differentiation-related protein. Molecular and Cellular Biology, 26: 1063-1076. 2006.

Clark AG. The role of haplotypes in candidate gene studies. Genetic Epidemiology, 27: 321-333. 2004.

DeRosa M, Gambacorta A, Nicolaus B, Chappa B and Albrecht P. Isoprenoid ethers: backbone of complex lipid of the archaebacterium Sulfolobus solfataricus. Biochimica et Biophysica Acta, 753: 249-256. 1983.

Gross DN, Miyoshi H, Hosaka T, Zhang HH, Pino EC, Souza S, Obin M, Greenberg AS and Pilch PF. Dynamics of lipid droplet-associated proteins during hormonally stimulated lipolysis in engineered adipocytes: stabilization and lipid droplet binding of adipose differentiation-related protein/ adipophilin. Molecular Endocrinology, 20: 459-466. 2006.

Horne BD and Camp NJ. Principal component analysis for selection of optimal SNP-sets that capture intragenic genetic variation. Genetic Epidemiology, 26: 11-21. 2004.

Imamura M, Inoguchi T, Ikuyama S, Taniguchi S, Kobayashi K, Nakashima $\mathbf{N}$ and Nawata H. ADRP stimulates lipid accumulation and lipid droplet formation in murine fibroblasts. American Journal of Physiology. Endocrinology and Metabolism, 283: 775-783. 2002.

Jiang XS and Groen AF. Chicken breeding with local breeds in China. Journal of Lipid Research, 13: 1482-1498. 2000.

Kim TH, Choi BH, Chang GW, Lee KT, Lee HY, Lee JH, Kim KS, Park CK and Moran C. Molecular characterization and chromosomal mapping of porcine adipose differentiationrelated protein (ADRP). Journal of Animal Breeding and Genetics, 122: 240-246. 2005.

Listenberger LL, Ostermeyer-Fay AG, Goldberg EB, Brown WJ and Brown DA. Adipocyte differentiation-related protein reduces lipid droplet association of adipose triglyceride lipase and slows triacylglycerol turnover. Journal of Lipid 
Research, 14: 2751-2761. 2007.

Lei M, Luo C, Peng X, Fang M, Nie Q, Zhang D, Yang G and Zhang XQ. Polymorphism of growth-correlated genes associated with fatness and muscle fiber traits in chickens. Poultry Science, 86: 835-842. 2007.

Magnusson B, Asp L, Bostrom P, Ruiz M, Stillemark-Billton P, Linden D, Boren $\mathbf{J}$ and Olofsson SO. Adipocyte differentiation-related protein promotes fatty acid storage in cytosolic triglycerides and inhibits secretion of very lowdensity lipoproteins. Arteriosclerosis, Thrombosis, and Vascular Biology, 26: 1566-1571. 2006.

Morris RW and Kaplan NL. The advantage of haplotype analysis in the presence of multiple disease susceptibility alleles. Genetic Epidemiology, 23: 221-233. 2002.

Nielsen KB, Sorensen S, Cartegni L, Corydon TJ, Doktor TK, Schroeder LD, Reinert LS, Elpeleg O, Krainer AR, Gregersen N, Kjems J and Andresen BS. Seemingly neutral polymorphic variants may confer immunity to splicinginactivating mutations: a synonymous SNP in exon 5 of MCAD protects from deleterious mutations in a flanking exonic splicing enhancer. American Journal of Human Genetics, 80: 416-432. 2007.

Prats CM, Donsmark K, Qvortrup C, Londos C, Sztalryd C, Holm HG and Ploug T. Decrease in intramuscular lipid droplets and translocation of HSL in response to muscle contraction and epinephrine. Journal of Lipid Research, 47: 2392-2399. 2006.

Qiu FF, Nie QH, Luo CL, Zhang DX, Lin SM and Zhang XQ. Association of single nucleotide polymorphisms of the insulin gene with chicken early growth and fat deposition. Poultry Science, 85: 980-985. 2006.

Rothschild MF and Soller M. Candidate gene analysis to detect genes controlling traits of economic importance in domestic livestock. Probe Newsletter for Agriculture Genomic, 8: 1320. 1997.

Salkinoja-Salonen, M, Middeldorp P, Briglia M, Valo R, Häggblom $\mathbf{M}$ and McBain, A. Biotechnology and biodegradation. In: Biotechnology and Biodegradation (Kamely D, Chakrabarty A, Omenn GS, Kamely D, Chakrabarty A, Omenn GS, eds). pp. 347-365. The Woodlands, Portfolio
Publishing Company, American. 1989.

Stephens M, Smith N and Donnelly P. A new statistical method for haplotype reconstruction from population data. American Journal of Human Genetics, 68: 978-989. 2001.

Wang Q, Li H, Li N, Leng L and Wang Y. Tissue expression and association with fatness traits of Liver Fatty Acid-Binding Protein gene in chicken. Poultry Science, 85: 1890-1895. 2006.

Wang SM, Hwang RD, Greenberg AS and Yeo HL. Temporal and spatial assembly of lipid droplet-associated proteins in 3 T3-L1 preadipocytes. Histochemistry and Cell Biology, 120: 285-292. 2003.

Wolins NE, Quaynor BK, Skinner JR, Schoenfish MJ, Tzekov A and Bickel PE. S3-12, Adipophilin, and TIP47 package lipid in adipocytes. Journal of Biological Chemistry, 280: 1914619155. 2005.

Wu G, Li G, Luo TH, Dong Y, Xu SJ, Huang W and Luo M. Adipose differentiation-related protein gene is associated with type 2 diabetes (in Chinese). Journal of Chinese Endocrinology and Metabolism, 20: 304-306. 2004.

Wu GQ, Deng XM, Li JY, Li N and Yang N. A potential molecular marker for selection against abdominal fatness in chickens. Poultry Science, 85: 1896-1899. 2006.

Zerehdaran S, Vereijken ALJ, Arendonk JAMV and Waaij EHVD. Estimation of genetic parameters for fat deposition and carcass traits in broilers. Poultry Science, 83: 521-525. 2004.

Zhang S, Li H and Shi H. Single marker and haplotype analysis of the chicken Apolipoprotein B gene T123G and D ${ }^{9} 500 D^{9-}$ polymorphism reveals association with body growth and obesity. Poultry Science, 85: 178-184. 2006.

Zhang XL, Jiang X, Liu YP, Du HR and Zhu Q. Identification of $A v a \mathrm{I}$ polymorphisms in the third intron of $G H$ gene and their associations with abdominal fat in chickens. Poultry Science, 86: 1079-1083. 2007.

Zhang ZR, Liu YP, Jiang X, Du HR and Zhu Q. Study on association of single nucleotide polymorphism of CAPN1 gene with muscle fibre and carcass traits in quality chicken populations. Journal of Animal Breeding and Genetics, 125: 258-264. 2008. 